\title{
Hubungan Pengetahuan dan Budaya dengan Terapi Uap Panas (Peusale) Pada Ibu Nifas di Kecamatan Lhoknga Kabupaten Aceh Besar Tahun 2021
}

\begin{abstract}
Putri Kurniawati
Akademi Kebidanan Saleha, Banda Aceh, Indonesia

Email : putriniazi87@gmail.com

Abstrak-Latar Belakang Data yang di peroleh dari Pukesmas Lhoknga Tahun 2018 AKI 453 jiwa dan AKB 4 jiwa, tahun 2019 AKI 8 jiwa dan AKB 2 jiwa pada tahun 2020 AKI 11 jiwa dan AKB 2 jiwa total 480. Perawatan masa Nifas merupakan suatu upaya yang dilakukan bidan, ibu nifas dan keluarga dengan tujuan agar kebutuhan nutrisi pada ibu nifas tercukupi, personal hygine terjaga Tujuan Penelitian: Untuk Mengetahui Hubungan Pengetahuan dan pengaruh Budaya dengan Terapi Uap Panas (peusale) pada Ibu Nifas di Kecamatan Lhoknga Kabupaten Aceh Besar Tahun 2021. Metode Penelitian: penelitian ini mengunakan metode analitik dengan pendekatan Cross Sectional yang dilakukan pada tanggal 14-19 September 2021 di lakukan di kercamatan Lhoknga Kabupaten Aceh Besar Populasi dalam penelitian ini adalah seluruh ibu Nifas Yang berjumlah 31 orang. Pengambilan sampel mengunakan Total sampling. Analisa data mengunakan analisa Univariat dan Bivariat dengan metode Chi-square test menunjukkan p-value sebesar 0,000 $<0,05$ Hasil Penelitian: Hasil uji statistik dengan Chi-square test menunjukkan p-value sebesar 0,000 $<0,05$ berarti ada pengaruh Pengetahuan dengan Budaya Terapi uap panas peusale. Berdasarkan tabel Chi-square test menunjukkan p-value sebesar 0,001 <0,05 maka ada pengaruh antara budaya dengan terapi uap panas pada ibu Nifas di Kecamatan Lhoknga Kabupaten Aceh Besar.
\end{abstract}

Kata Kunci: Pengetahuan; Budaya; Terapi Uap Panas; Ibu Nifas

Abstract-Back ground data obtained from the lhoknga publik helth center in 2018 AKI of 453 people and IMR of 4 people, in 2019 AKI of 8 people in 2020 AKI of 11 people in IMR of 2 people a total of 480 pospartum care is on effort mode by midwives, pospartum mothers and famillies with the aim that the nutritional needs of postpartum mothers are fulfillid, personal hygiene is maintained. Research objectives to dermine the relationship between knaowledge and the influence of cultur with hot steam therapy (peusale) on postpartum mothers in lhoknga district, aceh besar regency 2021. This research method used the method the analytikal cross sectional approach wich was carried out on september 14-19-2021 was carried out in the lhoknga sub-district. The population in this study was all 31 postpartum mothers. Sampling using total sampling data analysis using univariatee and bivariate analysis with the chi-squer test method showed a p-value of 0.0000 .05 research results. The results of statistical resets wit chi-squer test showed a p-value of $0.000<0.05$, meaning that there was an influence of knowledge with peusale steam therapy culture. Besed on the chi-squer thes table shows a p-value of $0.001<0.05$, there is an influence between culture and steam therapy for postpartum mothers in lhoknga district, aceh besar district.

Keywords: Knowledge; Culture; Stemt Therapy; Post Partum Mothers

\section{PENDAHULUAN}

Menurut data WHO (World Health Organitation) sebanyak 99\% Kematian ibu akibat masalah persalinan atau kelahiran terjadi di negara-negara berkembang. kematian ibu di negara-negara berkembang merupakan yang tertinggi dengan 450 kematian ibu per 100.000 kelahiran bayi hidup jika di bandingkan dengan rasio kematian ibu di sembilan negara maju dan 51 negara persemakmuran. Penyebab terjadinya Angka Kematian Ibu (AKI) terbesar di indonesia adalah pendarahan $28 \%$, infeksi $11 \%$ dan eklampsia 24\% (WHO, 2019). Pada tahun 2000, diperkirakan sebanyak 529.000 wanita meninggal karena komplikasi selama kehamilan dan persalinan, serta beberapa lainnya mengalami kecacatan. Rasio kematian ini diperkirakan 400/100/000 Kelahiran hidup, dan secara global wanita di Negara berpenghasilan rendah memiliki risiko kumulatif kematian seumur hidup pada 1 dalam 16 kasus, sedangkan di negara maju angka ini berada pada 1 dalam 2800 ibu (WHO, 2006).

Dinas Provinsi Aceh mencatat jumlah AKI tahun 2018 sebesar 139/100.000 KH, dengan mengunakan operasional yang telah ditetapkan keduanya, AKB di Aceh tahun 2018 sebanyak 9/ $1000 \mathrm{KH}$, jumlah lahir hidup sebanyak 101.296 jiwa, Jumlah ibu hamil di Aceh tahun 2018 sebanyak 127.730 jiwa, mencapai K1 112.866 jiwa atau 88\% dan K4 101. 901 jiwa atau 79\%, jumlah ibu bersalin sebanyak 121. 924 jiwa, jumlah ibu nifas sebanyak 101.906 jiwa, PUS sebanyak 897.823 jiwa, jumlah penguna KB baru sebanyak 0 jiwa, dan penguna KB aktif sebanyak 265.966 jiwa (DINKES, 2020). Berdasarkan keterangan dari Nurjannah et al., (2018) bahwa daerah Aceh Besar dan Kota Banda Aceh dikategorikan sebagai daerah kematian ibu melahirkan yang rendah.

Dinas Kesehatan Kabupaten Aceh Besar Tahun 2020 mencatat kasus lahir hidup dari 23 kecamatan total keseluruhan sebanyak 7.528 jiwa, di Kecamatan Lhoknga jumlah kematian ibu hamil 0 jiwa yang di laporkan, jumlah kematian ibu bersalin 4 jiwa, AKI nifas 8 jiwa, jadi total AKI terhitung dari tahun 2020 sebanyak 12 jiwa yang dilaporkan. Jumlah kematian neonatal( KN) sebanyak 25 jiwa per kabupaten. AKB laki-laki 26 jiwa per kabupaten. Angka kematian anak balita laki-laki 0 jiwa, jumlah total 51 jiwa. Jumlah KN perempuan 14 jiwa per kabupaten. Bayi perempuan 15 jiwa. Jumlah anak balita 0 jiwa. Jumlah total 29 jiwa (Suryawati, 2007). Baik di Negara maju maupun berkembang, perhatikan sangat tertuju pada ibu hamil dan persalinan (Padila, 2015). Oleh karena itu, dalam rangka mengurangi angka kematian ibu sesudah melahirkan dapat dikurangi dengan menjaga kesehatan ibu dengan cara perawatan yang tepat (Notoatmodjo, 2010).

Perawatan masa nifas diperlukan dalam periode ini karena merupakan masa kritis baik ibu maupun bagi bayinya. Ada sekitar $60 \%$ kematian ibu diakibatkan oleh pendarahan yang terjadi setelah persalinan dan $50 \%$ kematian masa nifas 


\section{Journal of Pharmaceutical and Health Research}

\section{Vol 3, No 1, Februari 2022, pp. 23-26}

ISSN 2721-0715 (media online)

DOI 10.47065/jharma.v3i1.1324

terjadi dalam 24 jam pertama (Heryani, 2012). Pelayanan pasca persalinan harus terselenggara pada masa itu untuk memenuhi kebutuhan ibu dan bayi, yang meliputi upaya pencegahan, deteksi dini dan pengobatan komplikasi dan penyakit yang mungkin terjadi, serta penyediaan pelayanan pemberian ASI, cara menjarangkan kehamilan, imunisasi, dan nutrisi bagi ibu. Periode pasca persalinan meliputi masa transisi kritis bagi ibu, bayi dan keluarganya secara fisiologis, emosional dan sosial. Perawatan ibu sehabis melahirkan sangat berpengaruh terhadap pengetahuan ibu tentang hal tersebut (Ratih, 2020). Sehingga penelitian ini perlu dilakukan untuk mengetahui hubungan pengetahuan ibu terhadap perawatan sehabis melahirkan dalam bentuk uap panas (Peusale) di daerah Lhonknga Aceh Besar. Karena keluarga dan budaya sangat mempengaruhi pengetahuan ibu terhadap perawatan sehabis melahirkan (Endriyani, 2020).

\section{METODOLOGI PENELITIAN}

Jenis penelitian yang dilakukan adalah bersifat analitik dengan pendekatan Crosssectional (Hardani, 2020) yaitu untuk mengetahui pengaruh budaya uap panas (peusale) Pada ibu Nifas di Kecamatan Lhoknga Kabupaten Aceh Besar Tahun 2021. Penelitian ini dilakukan di Kecamatan Lhoknga Kabupaten Aceh Besar. Sampel dalam penelitian ini adalah semua Ibu Nifas jumlah populasi yang terdapat di tempat penelitian. Sedangkan teknik yang digunakan dalam pengambilan sampel ini yaitu menggunakan teknik Total Sampling yaitu pengambilan populasi secara keseluruhan sebanyak 31 ibu Nifas. Instrumen dalam penelitian ini adalah angket yang berisi pertanyaan terkait judul penelitian. Data yang telah dihasilkan dianalisis menggunakan persentase dan disajikan dalam bentuk tabel untuk dideskripsikan.

\section{HASIL DAN PEMBAHASAN}

\subsection{Hasil}

1. Terapi budaya uap panas pada ibu Nifas

Tabel 1. Distribusi Frekuensi Terapi Uap Panas (Peusale) Pada ibu Nifas di Kecamatan Lhoknga Kabupaten Aceh Besar Tahun 2021

\begin{tabular}{|c|c|c|c|}
\hline $\mathrm{No}$ & Terapi uap panas & Frekuensi & Persetasi \% \\
\hline 1 & $\mathrm{Ya}$ & 23 & 74.1 \\
\hline 2 & Tidak & 8 & 25.8 \\
\hline & Total & 31 & 100 \\
\hline
\end{tabular}

Sumber (Data Primer Tahun 2021

Berdasarkan Tabel 1 diketahui dari 31 responden, yang mengunakan terapi uap panas yang menjawab ya 23 orang (74.1\%).

2. Pengetahuan

Tabel 2. Distribusi Frekuensi Pengetahuan Dengan Terapi Uap Panas (Peusale) Pada Ibu Nifas di Kecamatan Lhoknga Kabupaten Aceh Besar Tahun 2021.

\begin{tabular}{|c|c|c|c|}
\hline No & Pengetahuan & Frekuensi & Presentase $\%$ \\
\hline 1. & Baik & 22 & 70.9 \\
\hline \multirow[t]{2}{*}{2.} & Kurang & 9 & 29.0 \\
\hline & Total & 31 & 100 \\
\hline
\end{tabular}

Berdasarkan Tabel 2 diketahui dari 31 responden, pengetahuan baik sebanyak 22 orang (70.9\%).

3. Budaya

Tabel 3. Distribusi Frekuensi Budaya Terapi Uap Panas (Peusale) pada ibu Nifas di Kecamatan LhokngaKabupaten Aceh Besar Tahun 2021

\begin{tabular}{lccc}
\hline No & Budaya & Frekuensi & presentase $\%$ \\
\hline 1. & Ya & 20 & 64.5 \\
2. & Tidak & 11 & 35.4 \\
& Total & 31 & 100 \\
\hline \multicolumn{4}{c}{ Sumber data primer tahun 2021}
\end{tabular}

Berdasarkan Tabel 3 diketahui dari 31 responden, yang menjawab ya sebanyak 20 orang (64.5\%).

4. Hubungan Pengetahuan dengan terapi uap panas (peusale) 


\section{Journal of Pharmaceutical and Health Research}

\section{Vol 3, No 1, Februari 2022, pp. 23-26}

ISSN 2721-0715 (media online)

DOI 10.47065/jharma.v3i1.1324

Tabel 4. Distribusi Hubungan Pengetahuan dengan terapi uap panas (peusale) pada ibu Nifas di Kecamatan Lhoknga Kabupaten Aceh Besar Tahun 2021

\begin{tabular}{|c|c|c|c|c|c|c|c|c|}
\hline \multirow{3}{*}{ No } & \multirow{3}{*}{ Pengetahuan } & \multicolumn{4}{|c|}{ Terapi Uap Panas } & \multirow{2}{*}{\multicolumn{2}{|c|}{ Total }} & \multirow{3}{*}{$\mathrm{P}$ value } \\
\hline & & \multicolumn{2}{|c|}{$\mathrm{Ya}$} & \multicolumn{2}{|c|}{ Tidak } & & & \\
\hline & & $\mathrm{f}$ & $\%$ & $\mathrm{~F}$ & $\%$ & $f$ & $\%$ & \\
\hline 1 & Baik & 22 & 100 & 0 & 0,0 & 22 & 100 & \\
\hline \multirow[t]{2}{*}{2} & Kurang & 1 & 11,1 & 8 & 88,9 & 9 & 100 & 0,000 \\
\hline & Total & 23 & 74,2 & 8 & 25,8 & 31 & 100 & \\
\hline
\end{tabular}

Sumber data primer tahun 2021

Berdasarkan tabel 4 di atas diperoleh hasil penelitian bahwa dari 22 responden yang berpengetahuan baik yang melaksanakan terapi uap panas sebanyak 100\%, dari 9 responden yang berpengatahuanya kurang yang melakukan terapi uap panas sebanyak $11,1 \%$. Setelah dilakukan uji statistik dengan mengunakan (Chi-square test) di dapatkan nilai p-value sebesar $0,000<0,05$ maka ada hubungan pengetahuan ibu dengan terapi uap panas (peusale) pada ibu Nifas di Kecamatan Lhoknga Kabupaten Aceh Besar.

5. Hubungan budaya dengan terapi uap panas (peusale) pada ibu Nifas

Tabel 5. Distribusi Budaya Dengan Terapi Uap Panas (Peusale) Pada Ibu Nifas di Kecamatan Lhoknga Kabupaten Aceh besar Tahun 2021

\begin{tabular}{|c|c|c|c|c|c|c|c|c|}
\hline \multirow{3}{*}{ No } & \multirow{3}{*}{ Budaya } & \multicolumn{4}{|c|}{ Terapi Uap Panas } & \multirow{2}{*}{\multicolumn{2}{|c|}{ Total }} & \multirow{3}{*}{$\mathrm{P}$ value } \\
\hline & & \multicolumn{2}{|c|}{$\mathrm{Ya}$} & \multicolumn{2}{|c|}{ Tidak } & & & \\
\hline & & $\mathrm{f}$ & $\%$ & $\mathrm{~F}$ & $\%$ & $f$ & $\%$ & \\
\hline 1 & $\mathrm{Ya}$ & 20 & 100 & 0 & 0 & 20 & 64,5 & \\
\hline \multirow[t]{2}{*}{2} & Tidak & 3 & 27,3 & 8 & 72,7 & 11 & 35,5 & 0,001 \\
\hline & Total & 23 & 74,2 & 8 & 25,8 & 31 & 100,0 & \\
\hline
\end{tabular}

Berdasarkan tabel 5 di atas diperoleh hasil penelitian bahwa dari 20 responden yang budaya menjawab ya melaksanakan terapi uap panas sebanyak $100 \%$, dari 11 responden yang tidak mengunakan budaya terapi uap panas sebanyak $27,3 \%$.

Setelah dilakukan uji statistik dengan mengunakan (Chi-square test) di dapatkan nilai p-value sebesar 0,001 < 0,05 maka ada hubungan budaya ibu dengan terapi uap panas (peusale) pada ibu Nifas di Kecamatan Lhoknga Kabupaten Aceh Besar.

\subsection{Pembahasan}

1. Hubungan Pengetahuan Budaya Uap Panas (Peusale)

Berdasarkan tabel 5.5 di atas diperoleh hasil penelitian bahwa dari 22 responden yang berpengetahuan baik yang melaksanakan terapi uap panas sebanyak $100 \%$, dari 9 responden yang berpengatahuanya kurang yang melakukan terapi uap panas sebanyak $11,1 \%$. Setelah dilakukan uji statistik dengan mengunakan (Chi-square test) di dapatkan nilai p-value sebesar $0,000<0,05$ maka ada hubungan pengetahuan ibu dengan terapi uap panas (peusale) pada ibu Nifas di Kecamatan Lhoknga Kabupaten Aceh Besar.

2. Hubungan budaya dengan terapi uap panas (peusale)

Hasil penelitian menunjukkan bahwa terdapat hubungan budaya dengan terapi uap panas peusale, hal ini diketahui setelah dilakukan uji statistik berdasarkan tabel Chi-square test menunjukkan p-value sebesar 0,001 $<0,05$ maka ada pengaruh antara budaya dengan terapi uap panas pada ibu Nifas di Kecamatan Lhoknga Kabupaten Aceh Besar. Hasil penelitian menunjukkan bahwa terdapat hubungan Berdasarkan tabel Chi-square test menunjukkan $p$-value sebesar $0,000<0,05$ maka ada hubungan antara media infromasi pengunjung dengan penerapan prokes

\section{KESIMPULAN}

Berdasarkan tabel Chi-square test menunjukkan p-value sebesar 0,000 $<0,05$ maka ada hubungan pengetahuan dengan terapi uap panas peusale Pada Ibu Nifas di Kecamatan Lhoknga Kabupaten Aceh Besar Berdasarkan tabel Chi-square test menunjukkan p-value sebesar 0,001 <0,05 maka ada pengaruh antara budaya dengan terapi uap panas pada ibu Nifas di Kecamatan Lhoknga Kabupaten Aceh Besar.

\section{DAFTAR PUSTAKA}

Endriyani, A. (2020). Pengalaman ibu nifas terhadap budaya dalam perawatan masa nifas. Jurnal Kebidanan, 9(1), 45. https://doi.org/10.26714/jk.9.1.2020.45-52

Hardani. (2020). Metode penelitian kualitatif dan kuantitat... - Google Cendekia. (n.d.). Retrieved February 28, 2022, from https://scholar.google.com/scholar?hl=id\&as_sdt=0\%2C5\&q=Hardani.+2020.+Metode+penelitian+kualitatif+dan+kuantitatif. + Yogyakarta\%3A+CV.+Pustaka+ilmu\&btnG $=$ 


\section{Journal of Pharmaceutical and Health Research}

Vol 3, No 1, Februari 2022, pp. 23-26

ISSN 2721-0715 (media online)

DOI 10.47065/jharma.v3i1.1324

Heryani, R. (2012). Asuhan Kebidanan Ibu Nifas dan Menyusui. Jakarta: Trans Info Media.

Notoatmodjo, S. (2010). Ilmu perilaku kesehatan. http://repo.unikadelasalle.ac.id/index.php?p=show_detail\&id=6161\&keywords=

Nurjannah, N., Maria, I., Rildayani, R., \& ... (2018). Analisis Spasial Angka Kematian Ibu (AKI) dengan Rasio Bidan, serta Cakupan Persalinan oleh Tenaga Kesehatan Di Provinsi Aceh Tahun 2017. Jurnal Kedokteran ..., 1(3), 7-14. http://www.jknamed.com/jknamed/article/view/57

Padila, P. (2015). Asuhan Keperawatan Maternitas... - Google Cendekia. (n.d.). Retrieved February 28, 2022, from https://scholar.google.com/scholar?hl=id\&as_sdt=0\%2C5\&q=Padila\%2C+P.+\%282015\%29.+Asuhan+Keperawatan+Maternit as+1.+Yogyakarta\%3A+Nuha+Medika\&btnG=

Ratih, R. H. (2020). Pengetahuan dan Sikap Ibu Nifas tentang Perawatan Luka Perineum. Jurnal Kesmas Asclepius, 2(1), 34-43. https://doi.org/10.31539/JKA.V2I1.592

Suryawati, C. (2007). Faktor Sosial Budaya dalam Praktik Perawatan Kehamilan, Persalinan, dan Pasca Persalinan (Studi di Kecamatan Bangsri Kabupaten Jepara). Jurnal Promosi Kesehatan Indonesia, 2(1), 21-31-31. https://doi.org/10.14710/jpki.2.1.21-31

W. H. O. (2006). Making a difference in countries: strategic approach to improving maternal and newborn survival and health: ensuring skilled care for every birth. https://apps.who.int/iris/bitstream/handle/10665/69468/a89864_rus.pdf

W. H. O (2019). Maternal mortality: evidence brief. https://apps.who.int/iris/bitstream/handle/10665/329886/WHO-RHR-19.20eng.pdf 